\title{
Article \\ Fetal Zone Steroids and Estrogen Show Sex Specific Effects on Oligodendrocyte Precursor Cells in Response to Oxidative Damage
}

\author{
Donna Elizabeth Sunny ${ }^{1, *}$, Elke Hammer ${ }^{2}{ }^{\circledR}$, Till Ittermann ${ }^{3}$, Elisabeth Luise Krüger ${ }^{1}$, Stephanie Hübner ${ }^{1}$, \\ Michaela Friederike Hartmann ${ }^{4}{ }^{\mathbb{D}}$, Stefan Alexander Wudy ${ }^{4}$, Uwe Völker ${ }^{2}{ }^{\circledR}$ and Matthias Heckmann ${ }^{1}$ \\ 1 Department of Neonatology and Pediatric Intensive Care, University of Medicine Greifswald, \\ 17475 Greifswald, Germany; el.kruger@yahoo.de (E.L.K.); stephanie.huebner1@gmx.de (S.H.); \\ matthias.heckmann@uni-greifswald.de (M.H.) \\ 2 Department of Functional Genomics, University of Medicine Greifswald, 17475 Greifswald, Germany; \\ hammer@uni-greifswald.de (E.H.); voelker@uni-greifswald.de (U.V.) \\ 3 Institute for Community Medicine, University of Medicine Greifswald, 17475 Greifswald, Germany; \\ till.ittermann@uni-greifswald.de \\ 4 Pediatric Endocrinology \& Diabetology, Laboratory for Translational Hormone Analytics, Steroid Research \& \\ Mass Spectrometry Unit, Center of Child and Adolescent Medicine, Justus Liebig University, \\ 35392 Giessen, Germany; michaela.hartmann@paediat.med.uni-giessen.de (M.F.H.); \\ stefan.wudy@paediat.med.uni-giessen.de (S.A.W.) \\ * Correspondence: sunnyd@uni-greifswald.de
}

Citation: Sunny, D.E.; Hammer, E.; Ittermann, T.; Krüger, E.L.; Hübner, S.; Hartmann, M.F.; Wudy, S.A.; Völker,

U.; Heckmann, M. Fetal Zone Steroids and Estrogen Show Sex Specific Effects on Oligodendrocyte Precursor Cells in Response to Oxidative Damage. Int. J. Mol. Sci. 2021, 22, 6586. https://doi.org/ $10.3390 /$ ijms 22126586

Academic Editor: Kin Sing Stephen Lee

Received: 15 April 2021

Accepted: 16 June 2021

Published: 19 June 2021

Publisher's Note: MDPI stays neutral with regard to jurisdictional claims in published maps and institutional affiliations.

Copyright: (c) 2021 by the authors. Licensee MDPI, Basel, Switzerland. This article is an open access article distributed under the terms and conditions of the Creative Commons Attribution (CC BY) license (https:/ / creativecommons.org/licenses/by/ $4.0 /)$.
Abstract: Oxygen causes white matter damage in preterm infants and male sex is a major risk factor for poor neurological outcome, which speculates the role of steroid hormones in sex-based differences. Preterm birth is accompanied by a drop in $17 \beta$-estradiol (E2) and progesterone along with increased levels of fetal zone steroids (FZS). We performed a sex-based analysis on the FZS concentration differences in urine samples collected from preterm and term infants. We show that, in preterm urine samples, the total concentration of FZS, and in particular the $16 \alpha-\mathrm{OH}$-DHEA concentration, is significantly higher in ill female infants as compared to males. Since we previously identified Nup133 as a novel target protein affected by hyperoxia, here we studied the effect of FZS, allopregnanolone (Allo) and E2 on differentiation and Nup133 signaling using mouse-derived primary oligodendrocyte progenitor cells (OPCs). We show that the steroids could reverse the effect of hyperoxia-mediated downregulation of Nup133 in cultured male OPCs. The addition of FZS and E2 protected cells from oxidative stress. However, E2, in presence of $16 \alpha-\mathrm{OH}$-DHEA, showed a negative effect on male cells. These results assert the importance of sex-based differences and their potential implications in preterm stress response.

Keywords: preterm birth; oligodendrocyte precursor cells; fetal zone steroids; estradiol; hyperoxia; sex-based difference; differentiation

\section{Introduction}

Preterm birth is one of the leading causes of neonatal morbidity and mortality [1,2]. These babies are at a high risk of severe developmental disabilities as prematurity is associated with complex adverse consequences. Alterations in the pre-conceptional, fetal and early neonatal periods lead to profound phenotypic, endocrine and metabolic consequences. This includes perinatal exposure to oxidative stress which has been implicated in the pathology of a number of diseases related to prematurity, especially wide-spread white matter damage in the brain [3]. Moreover, there is accumulating evidence that females have an advantage over males with a better outcome in the perinatal period, particularly after preterm birth [4]. This gender-based difference points towards a possible role of hormones and, considering its relation to hyperoxia, it becomes important to identify the underlying reasons for differential responses. 
During pregnancy, maternal progesterone level increases and the main source is the placenta. Apart from the placenta, the adrenal glands also synthesize progesterone under the control of adrenocorticotropic hormone (ACTH) due to which its secretion by the adrenal glands can increase in response to stress [5]. Not only progesterone, but $17 \beta-$ estradiol (E2) plasma levels also increase up to 100 -fold $(15,000 \mathrm{pg} / \mathrm{mL}$, approximately $55 \mathrm{nM}$ ) compared to the plasma estrogen concentrations in non-pregnant females [6,7]. The fetus is also exposed to increasing hormone levels during its development. The presence of high amounts of estrogen is considered to be critical for normal brain development [8,9]. Several experimental studies have highlighted that the female sex hormones represent potential neuroprotective agents against acute and chronic injuries in the brain [10-12]. But at the time of birth, after the umbilical cord is clamped, E2 level decreases by a factor of 100 within $24 \mathrm{~h}$ [13]. In humans, this estrogen synthesis by the placenta during pregnancy is largely dependent on androgens from the fetal and maternal adrenal glands. Fetal adrenal steroids are the source of about half of the estrone and estradiol and $90 \%$ of the estriol in the maternal circulation [14]. The human fetal adrenal cortex is an active endocrine organ that produces steroid hormones, which regulate intrauterine homeostasis and the maturation of the fetal organ system. An active steroidogenic specialized compartment of the fetal adrenal cortex is called the fetal zone, whose mass increases in utero up to term and then declines rapidly after birth. The fetal zone, together with the placenta, forms an effective steroid exchange channel and this functional association is termed as the "feto-placental unit" $[15,16]$.

As a result of preterm birth, the feto-placental unit is disrupted and the synthesis of estrogen and progesterone in the placenta stops. However, the fetal zone of the preterm infant continues to synthesize steroid precursor molecules which are collectively called fetal zone steroids (FZS). FZS mainly comprise of dehydroepiandrosterone (DHEA), which is the main precursor molecule for estrogen synthesis. This DHEA is converted into more hydrophilic metabolites that are eventually excreted from the body through urine. We and others have reported that the urinary excretion of $3 \beta-\mathrm{OH}-5$-ene steroids in preterm born infants is significantly higher for a longer period of time and does not approach that of term infants before 40 weeks postmenstrual age [17,18]. Additionally, a persistent higher plasma concentration of DHEA-sulfate (DHEAS) was found in preterm infants from the day of birth until 10 months of age, when compared to that of term infants [19]. Studies have reported that, even though high DHEAS levels during the first week of life may reflect the sudden discontinuation of the placental metabolism of circulating DHEAS into estrogens at birth, it might also partly represent a stress response [20]. Since preterm birth is accompanied by a drop in estrogen level and an increase in the levels of these precursor molecules to which the developing brain is normally exposed, the precise role of these precursor molecules in brain development needs to be addressed. If investigated in detail, these molecules might as well prove to be novel but endogenously synthesized neuroprotective agents that can promote cell survival and maturation.

By means of our previous study, we have experimentally shown that these FZS show a neuroprotective effect comparable to that of E2, in a hyperoxia induced cell death model of immature glial cells [21]. However, these experiments did not consider sex differences. Therefore, we have recently demonstrated that oxidative stress severely affects cellular functions related to energy metabolism, stress response, and maturation in male derived mouse primary oligodendrocyte progenitor cells (OPCs), whereas the female cells remain largely unaffected. We also uncovered Nup133 as a novel regulator and have shown how OPC differentiation and nuclear respiratory factor 1 (Nrf1) oxidative stress responses are mediated differentially by Nup133 and the classical estrogen receptor alpha (ER $\alpha)$ in male and female derived OPCs [22].

In the current study, we address the concentration changes in urinary FZS concentrations in preterm and term infants by classifying them based on gender and wellness. Further, we show the differential response of male and female derived OPCs to oxidative stress in presence of FZS, allopregnanolone ( $3 \alpha$-Hydroxy-5 $\alpha$-pregnan-20-one; Allo) and E2. In the 
context of Nup133 signaling, we explain how the FZS, Allo and E2 have a neuroprotective role but at the same time, a differential effect on the maturation of male and female derived primary OPCs. Based on the results, we also project a possible explanation for the differences in urinary steroid profiles observed in preterm infants and their potential implications.

\section{Results}

\subsection{Fetal Zone Steroid Amounts Differ in the Urine of Preterm Male and Female Infants}

Our previous experimental data suggested endogenous neuroprotection by FZS [20] which are synthesized in high concentrations postnatally in preterm infants [17]. In humans, these steroid hormone precursors might play potential roles in brain development and in combating stress. Even though there have been studies about the neuroactive nature of some of these steroids in different models [23], their abundance in preterm infants has not yet been characterized completely. This includes characterization of the prevalence of these FZS in different body fluids and tissues based on gestational age, sex, illness, etc. We, therefore, analyzed urine samples collected from human preterm and term infants along a period of time starting from day 1 to day 3 after birth using GC-MS and characterized the data with respect to sex and illness.

Differences in fetal zone steroid median concentrations between well terms and well preterms were visualized by box plots. Associations between groups of infants (ill preterms, well preterms and terms) with corresponding fetal zone steroid concentrations were analyzed by median regression models in the whole population as well as stratified by sex.

The urinary steroid profile showed a significantly higher level of total FZS in the urine of well preterm infants when compared to well term infants (Figure 1A). Upon analyzing the concentration profiles in well and ill preterm infants stratified by sex, we found that there was no difference in the total FZS levels in well preterm male and female groups; whereas, when comparing between the well and ill groups, FZS levels were significantly higher in both ill male and female infants, with a still higher concentration (non-significant) in ill female infants as compared to males (Figure 1B).

A

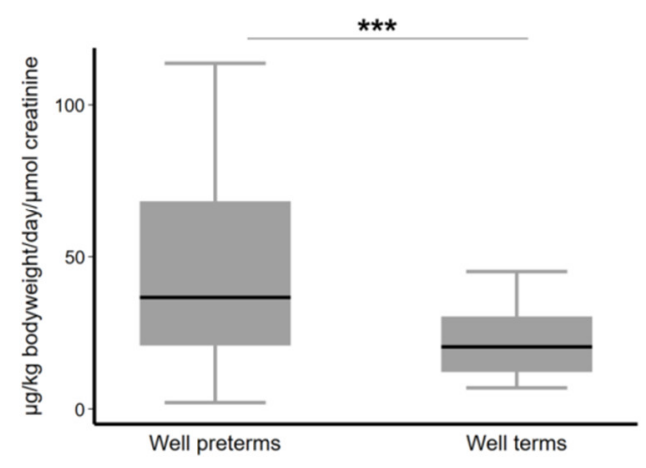

B

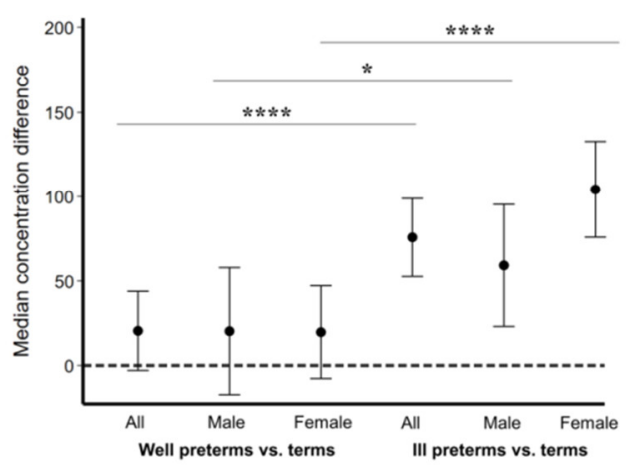

Figure 1. Fetal zone steroids (FZS) are excreted in high amounts in preterm infant urine. (A) Total FZS excretion in healthy term ( $>37$ weeks gestational age, $n=42$ ) and healthy preterm ( $<37$ weeks gestational age, $n=71$ ) infants during the first three days after birth measured in $\mu \mathrm{g} / \mathrm{kg}$ bodyweight/day $/ \mu \mathrm{mol}$ creatinine. ${ }^{* * *} p<0.001$ as determined by Wilcoxon-Mann-Whitney test. Median and $95 \%$ confidence interval are given. (B) A comparison of the total FZS excretion in healthy male preterm $(<37$ weeks gestational age, $n=42)$ and healthy female preterm ( $<37$ weeks gestational age, $n=29)$ infants compared to sick male preterm ( $<37$ weeks gestational age, $n=38$ ) and sick female preterm ( $<37$ weeks gestational age, $n=26$ ) infants during the first three days after birth. ${ }^{*} p<0.05,{ }^{* * * *} p<0.0001$ (median regression models). The beta coefficients and the belonging $95 \%$ confidence intervals were plotted. A whole $95 \%$ confidence interval above 0 is considered statistically significant. 


\subsection{Concentration of $16 \alpha-O H-D H E A$ and Other FZS Increases in Ill Female Preterm Infants}

As it is known, $16 \alpha$-OH-DHEA is a precursor of $16 \alpha$-hydroxylated estrogens. DHEA and DHEAS produced by the fetal zone are the most abundant circulating steroids; they are first hydroxylated at $16 \alpha$-position in the fetal liver to form $16 \alpha-\mathrm{OH}$-DHEA and $16 \alpha$ $\mathrm{OH}$-DHEAS, and are finally aromatized in the placenta following transport across the feto-placental barrier $[24,25]$. In our data, $16 \alpha-\mathrm{OH}-\mathrm{DHEA}$ was found to be present in very high concentrations when compared to the other detected metabolites in the preterm group (Figure 2A), and significantly higher in the healthy preterm group than in the terms, (Figure 2B) with values going up to $17.5(6.1-154.3) \mu \mathrm{g} / \mathrm{kg}$ bodyweight per day and $\mu \mathrm{mol}$ creatinine $(n=7)$ at 25 weeks gestational age compared to $0.6(0.1-1.8) \mu \mathrm{g} / \mathrm{kg}$ bodyweight per day and $\mu \mathrm{mol}$ creatinine $(n=20)$ at 39 weeks gestational age. Further comparison based on sex and being well showed that $16 \alpha-\mathrm{OH}$-DHEA was present in significantly higher concentration in all ill preterm infants than the healthy ones. A particularly higher significant difference was observed between healthy and ill preterm females (Figure 2C). However, upon considering only the early preterm infants ( $<30$ weeks gestational age), we saw that $16 \alpha-\mathrm{OH}-\mathrm{DHEA}$ was slightly higher in the healthy as well as sick male infants (Figure 2D). Additionally, we also looked at the concentration differences in the most abundant DHEA-metabolite androstene- $3 \beta, 17 \alpha$-diol and the pregnenolone metabolite $21-\mathrm{OH}-\mathrm{P} 5$-olone. In the case of androstene-3 $\beta, 17 \alpha$-diol we found a similar trend as $16 \alpha-$ $\mathrm{OH}-\mathrm{DHEA}$ with significantly higher concentration in all ill preterm infants as well as in the case of ill female preterm infants when compared to all healthy preterm and the healthy female preterm group respectively (Appendix A Figure A1A). But in the case of 21-OH-P5-olone, although the concentrations in well preterm infants were seen to be almost similar to the term group, it showed significantly higher levels in male as well as female ill preterm infants when compared to their well counterparts (Appendix A Figure A1B). Hence, in an attempt to understand the consequences of these observed differences in FZS concentrations, we tested $16 \alpha$-OH-DHEA and Adiol (androstene- $3 \beta, 17 \beta$-diol) as proxies of the FZS versus estradiol and allopregnanolone on the mouse OPCs.

\subsection{FZS and Allopregnanolone Have a Protective Effect on Both Male and Female OPCs}

To evaluate the impact of hormones on the neurological development, we tested the effect of $16 \alpha-\mathrm{OH}$-DHEA along with Adiol (androstene- $3 \beta, 17 \beta$-diol) and Allo on the maturation of OPCs. As described previously, using a primary mouse-derived OPC culture model, we performed experiments with separate male and female derived OPCs simultaneously. The cells were subjected to an optimum treatment regime of $80 \%$ oxygen shock for $24 \mathrm{~h}$ and were then returned back to normal oxygen conditions and were allowed to recover and differentiate for 4 days. At the time of $\mathrm{O}_{2}$ shock, the OPCs were largely immature and vulnerable to oxygen damage. As we have previously shown, the male OPCs are severely affected by hyperoxia leading to impairment of maturation whereas the female cells remain largely unaffected [22]. This impairment of maturation was accompanied by the downregulation of the nucleoporin protein Nup133 and its direct downstream target nuclear respiratory factor 1 (Nrf1) in the male cells. The female cells seemed to be rendered resistant due to synergistic protection via the estrogen receptor alpha $(\mathrm{ER} \alpha)$ which was upregulated following hyperoxia in female but not in male cells. Both Nup133 and ER $\alpha$ regulate mitochondrial function and oxidative stress response by transcriptional regulation of Nrf1 [22]. It was interesting to see that the administration of FZS and Allo had a positive effect on the maturation of male OPCs post hyperoxia (Figure $3 \mathrm{~A}$ ), as seen by changes in myelin associated glycoprotein (MAG) levels. In the case of female cells, considering the fact that the oxygen treatment itself did not show any reduction in MAG levels, treatment with the steroids seems to have broadly no additional effect. Similarly, under normoxic conditions, where protein levels after treatment with all three steroids were increased in the case of male cells, in the female derived cells they were mostly comparable to normal levels (CTRL_N). On looking at the expressions of Nup133 and ER $\alpha$, we see that the $E R \alpha$ protein abundance tends to increase in the female cells under hyperoxic conditions when treated with the steroids, whereas in the male cells it remains unchanged. On 
the other hand, Nup133 expression shows a trend towards increase after treatment with Adiol and Allo in both male and female cells under hyperoxia, but not when cells were treated with $16 \alpha-\mathrm{OH}$-DHEA. This shows that the observed effect on maturation might be mediated not only by Nup133 but also by ER $\alpha$ in the female cells, as previously hypothesized [22]. Whereas, in male cells, this effect seems to be mediated mainly by Nup133. However, $16 \alpha$-OH-DHEA seems to differ in its mechanism of action (Figure 3B,C). Hence, we show that these steroids have a positive effect on stress response and maturation post hyperoxia, especially in the male cells, and at the same time they can have discrete mechanisms of actions.

A

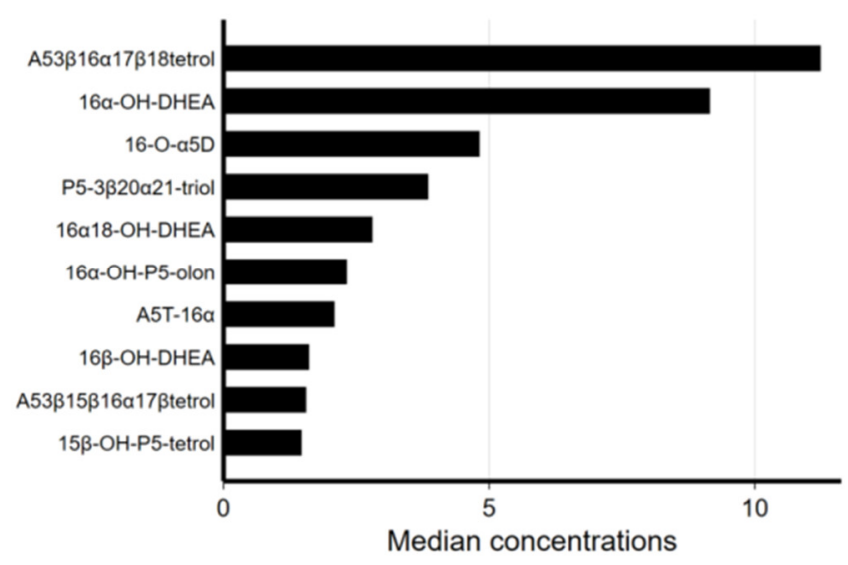

C

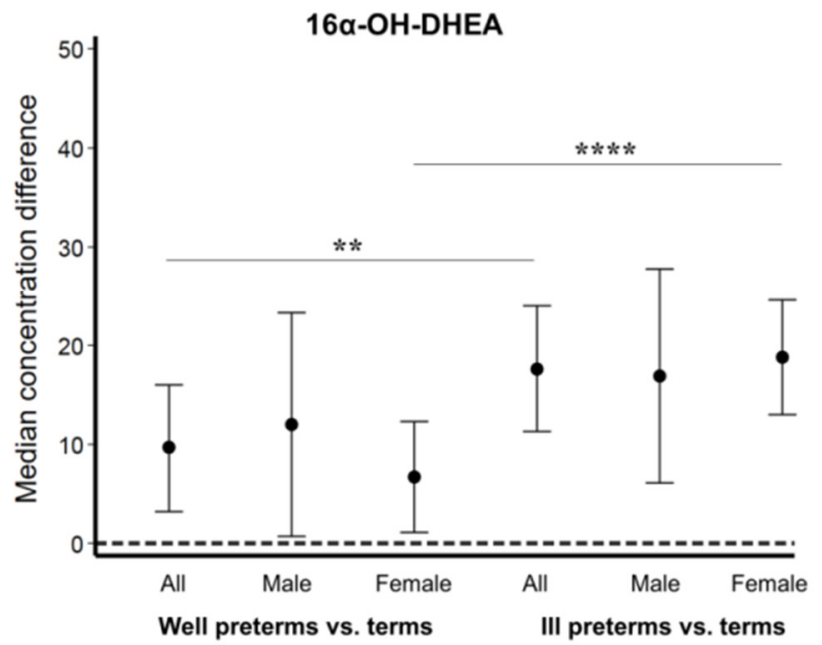

B

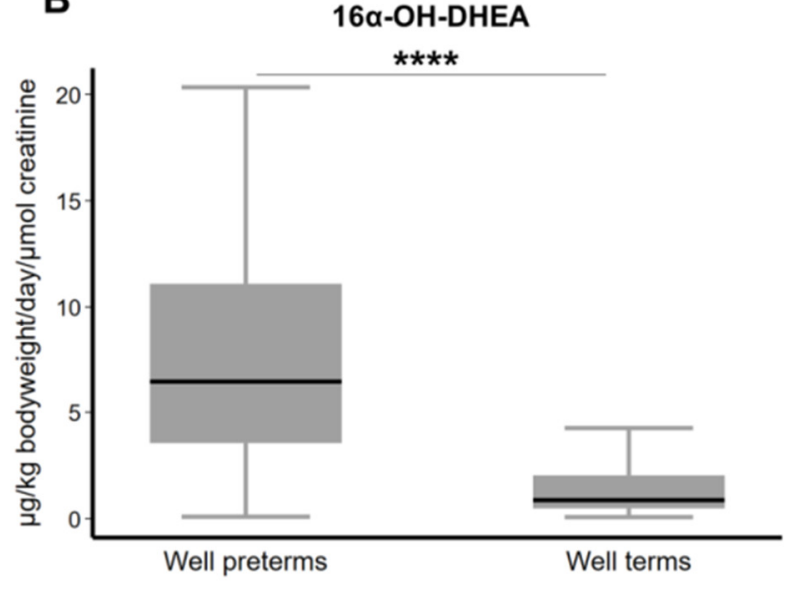

D

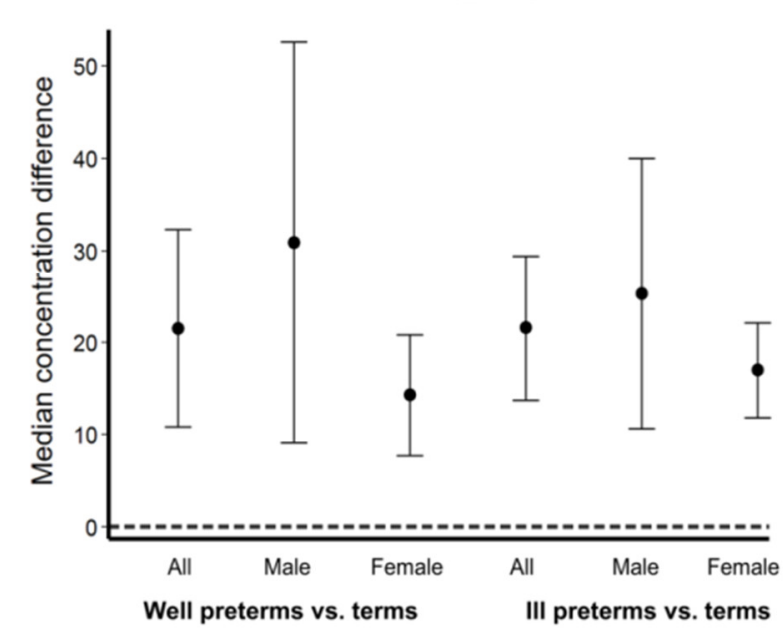

Figure 2. Urine concentration of selected FZS stratified by sex and wellness. (A) Concentrations of the ten highest analyzed FZSs during the first 3 days after birth in all preterm infants (well and ill, $n=135$ ). (B) 16 $\alpha$-OH-DHEA concentration in preterm $(n=135)$ and term $(n=63)$ infants. ${ }^{* * * *} p<0.0001$ as determined by Wilcoxon-Mann-Whitney test. Median and $95 \%$ confidence interval are given. (C) $16 \alpha-\mathrm{OH}-\mathrm{DHEA}$ excretion in well male preterm ( $<37$ weeks gestational age, $n=42)$ and well female preterm ( $<37$ weeks gestational age, $n=29)$ infants compared to ill male preterm $(<37$ weeks gestational age, $n=38)$ and ill female preterm $(<37$ weeks gestational age, $n=26)$ infants during the first three days after birth. ${ }^{* *} p<0.01,{ }^{* * * *} p<0.0001$ (median regression models). (D) 16 $\alpha-\mathrm{OH}-\mathrm{DHEA}$ excretion in well male early preterm ( $<30 \mathrm{weeks}$ gestational age, $n=7)$ and well female early preterm ( $<30$ weeks gestational age, $n=10)$ infants compared to ill male early preterm ( $<30$ weeks gestational age, $n=23$ ) and ill female early preterm ( $<30$ weeks gestational age, $n=21)$ infants during the first three days after birth. The beta coefficients and the belonging $95 \%$ confidence intervals were plotted. A whole $95 \%$ confidence interval above 0 is considered statistically significant. 


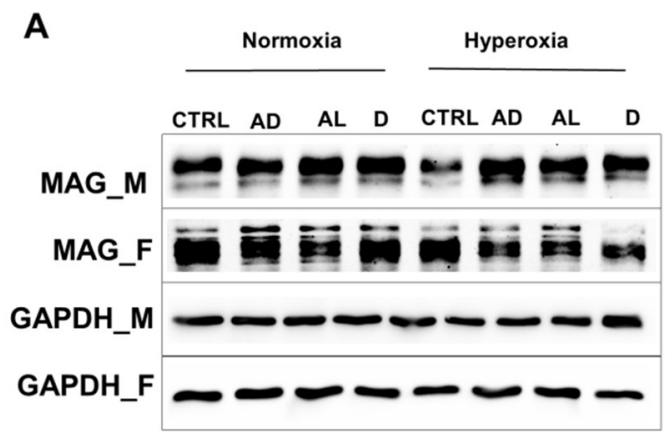

B

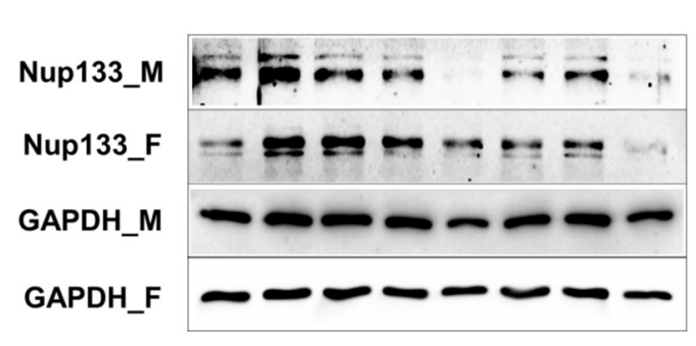

C

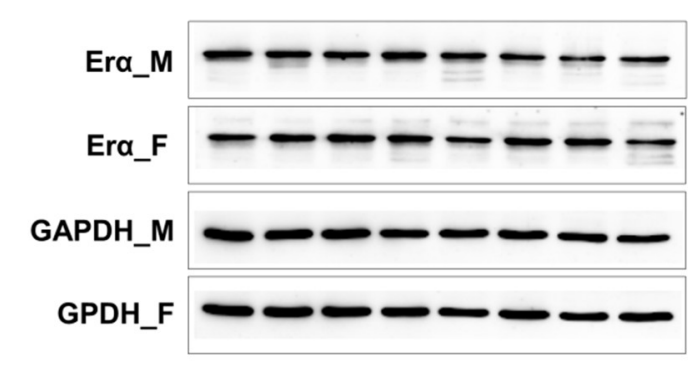

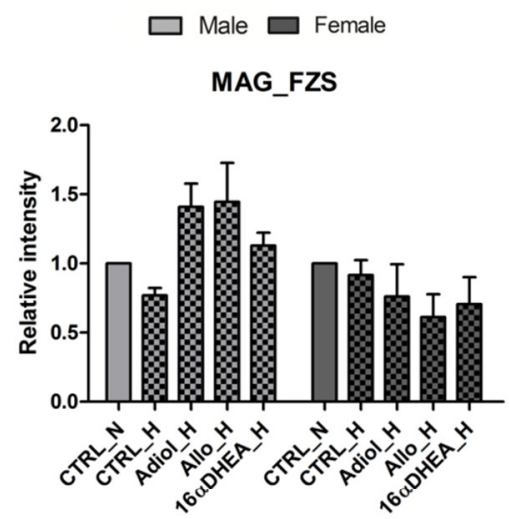

Nup133_FZS

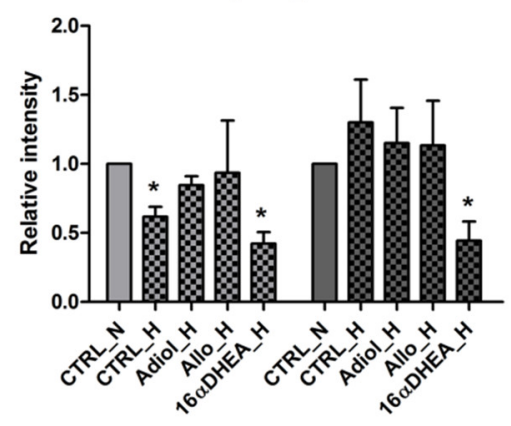

$E R \alpha \_F Z S$

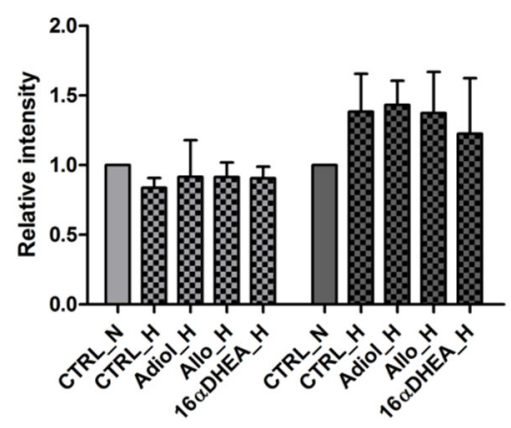

Figure 3. FZS and E2 show discrete effects on male and female OPCs. Western blot results showing the expression of (A) MAG, (B) Nup133 and (C) ER $\alpha$ in OPCs after treatment with $100 \mathrm{nM}$ Adiol (AD), $100 \mathrm{nM}$ Allopregnanolone (AL) and $100 \mathrm{nM} \mathrm{16 \alpha -OH-DHEA} \mathrm{under} \mathrm{normoxia} \mathrm{and} \mathrm{hyperoxia.} \mathrm{All} \mathrm{data} \mathrm{are} \mathrm{representative} \mathrm{of} \mathrm{at} \mathrm{least} \mathrm{three} \mathrm{independent}$ experiments. Bars and error represent mean \pm SEM of replicate measurements. Significant differences from normoxia control are indicated by * $p<0.05$ (Student's $t$-test).

\subsection{Estradiol in Presence of $16 \alpha O H$-DHEA Exerts a Negative Effect on the Maturation of Male Derived Cells}

Since preterm birth is associated with a drop in estrogen and progesterone levels, it has been advocated that substituting estrogen to intrauterine levels can be beneficial $[13,26-28]$. These preliminary clinical studies to substitute these steroids were carried out in female preterm infants only and have failed to confirm significantly improved neurological outcomes. Considering the high amounts of circulating FZS in preterm infants, more experimental evidence is required to decipher the effect of any additional steroid substitution in the presence of FZS and its implications in male and female infants with respect to neuroprotection. In that context, we have previously shown that the FZS might provide endogenous neuroprotection which could interfere with E2-mediated protection [21]. However, we did not investigate any sex-based differences and therefore, here, we checked the effect of $16 \alpha-\mathrm{OH}$-DHEA on the differentiation of OPCs in the presence of E2 (co-treatment). We treated male and female 
OPCs with $100 \mathrm{nM}$ E2 alone and in combination with $100 \mathrm{nM} 16 \alpha-\mathrm{OH}$-DHEA. When giving high oxygen treatment for $24 \mathrm{~h}$, we found that $\mathrm{E} 2 \mathrm{had}$ a positive effect on MAG expression in the male cells which was, however, diminished by co-treatment (Figure 4A) even though under normoxic conditions the co-treatment increased MAG expression. We checked the expression of Nup133 and ER $\alpha$ under the same treatment conditions and found that the abundance of both these proteins was decreased in the co-treatment group in male cells post hyperoxia (Figure $4 B, C$ ). Whereas in the female cells, an increased abundance was observed in the case of both Nup133 and ER $\alpha$ (Figure 4B,C). In general, increased protein levels were observed under normoxic conditions. This negative effect of the co-treatment on the male cells, along with the observed higher levels of $16 \alpha-\mathrm{OH}$-DHEA in the urine of early $(<30$ weeks gestational age) male preterm infants in both well and ill groups (Figure 2D), again points towards the importance of sex differences with respect to circulating FZS while considering hormone substitutions as a therapy in preterm infants. Table 1 summarizes the differences between co-treatment and single steroid treatments.

A

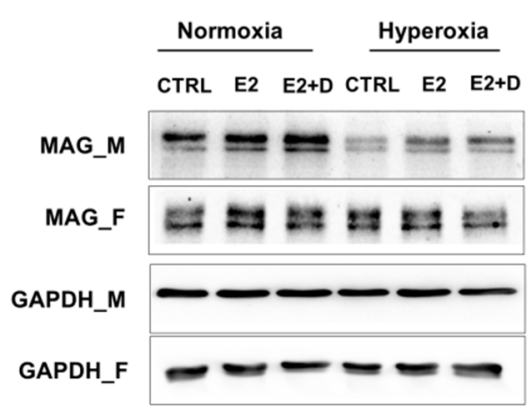

MAG_E2 effect

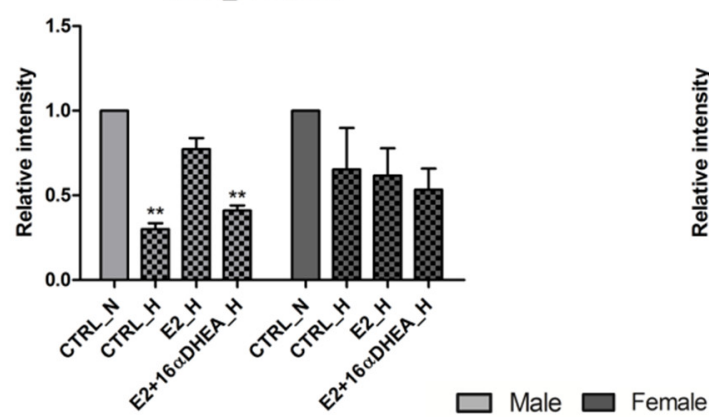

B

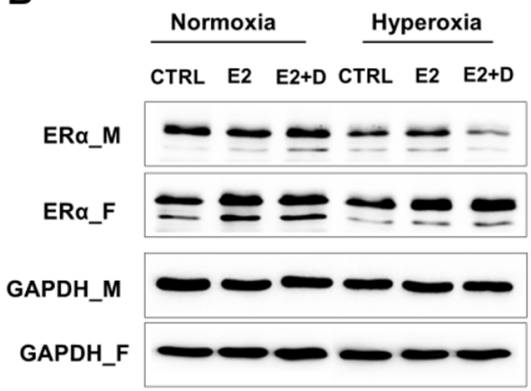

$E R \alpha_{-} E 2$ effect

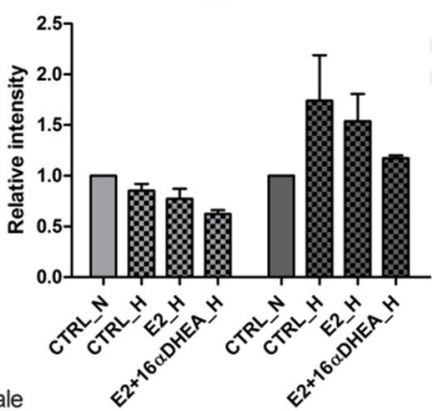

C

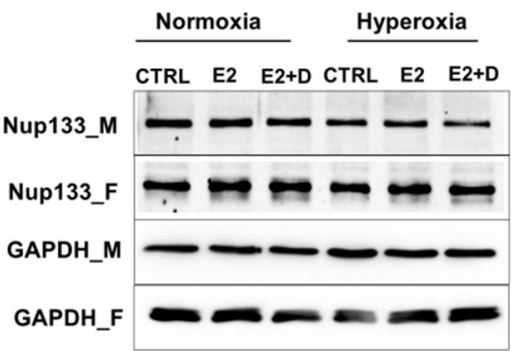

NUP133_E2 effect

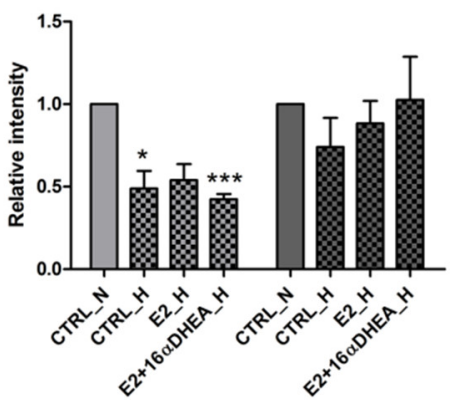

Figure 4. Effect of E2 and 16 $\mathrm{OH}$-DHEA co-treatment. Western blot results showing the expression of (A) MAG, (B) ER $\alpha$ and (C) Nup133 in OPCs after treatment with $100 \mathrm{nM} 17-\beta$ estradiol (E2) alone and E2 in combination with $100 \mathrm{nM} 16 \alpha-\mathrm{OH}-\mathrm{DHEA}(\mathrm{E} 2+\mathrm{D})$ under normoxia and hyperoxia. All data are representative of at least three independent experiments. Bars and error represent mean \pm SEM of replicate measurements. Significant differences from normoxia control are indicated by ${ }^{*} p<0.05,{ }^{* *} p<0.01,{ }^{* *} p<0.001$ (Student's $t$-test). 
Table 1. Impact of steroids on OPCs in comparison to the untreated normoxic control cells. For assessing the effects, the normoxia control has been considered as the base and the effects of the steroids on the male and female derived cells under hyperoxic conditions have been interpreted accordingly.

\begin{tabular}{|c|c|c|c|c|c|c|c|c|c|c|}
\hline & \multicolumn{5}{|c|}{ Normoxia } & \multicolumn{5}{|c|}{ Hyperoxia } \\
\hline & Adiol & Allo & $16 \alpha \mathrm{D}$ & E2 & $\mathrm{E} 2+16 \alpha \mathrm{D}$ & Adiol & Allo & $16 \alpha \mathrm{D}$ & E2 & $E 2+16 \alpha D$ \\
\hline \multicolumn{11}{|c|}{$\begin{array}{l}\text { Impact on } \\
\text { maturation }\end{array}$} \\
\hline Male & ++ & +++ & +++ & ++ & +++ & ++ & + & + & no & - \\
\hline Female & + & + & ++ & + & + & no & no & no & no & no \\
\hline \multicolumn{11}{|l|}{$\begin{array}{c}\text { Impact on } \\
\text { Nup133 }\end{array}$} \\
\hline Male & + & + & + & + & no & + & + & - & no & - \\
\hline Female & ++ & ++ & + & + & + & + & + & - & + & + \\
\hline \multicolumn{11}{|c|}{ Impact on ER $\alpha$} \\
\hline Male & no & no & no & no & + & no & no & no & no & - \\
\hline Female & + & + & + & ++ & ++ & ++ & ++ & + & ++ & ++ \\
\hline
\end{tabular}

\subsection{6 $\alpha-, \mathrm{OH}-\mathrm{DHEA}$ Activates Different Mechanisms in Male and Female Cells}

In our previous study we evaluated the receptors involved in the protective effect observed by FZS and found that the neuroprotection by FZSs was highly dependent on the cell type-specific expression of aromatases, the receptor repertoire and the potency of the fetal zone steroids towards these receptors [21]. However, in the primary OPCs we found an upregulation of $\mathrm{ER} \alpha$ as a response to hyperoxic treatment in the female cells [22] and, therefore, to understand the sex specific effect of $16 \alpha$-OH-DHEA on this ER response, we performed a co-treatment of $16 \alpha-\mathrm{OH}$-DHEA with ICI 182, 780 (ICI) which is an estrogen receptor antagonist. In the male derived cells, the co-treatment resulted in an increase in the protein levels of MAG as well as Nup133 under normoxic and hyperoxic conditions. Whereas, in the female cells, the increase observed under normoxic condition was diminished upon hyperoxia. (Figure 5). Treatment with ICI alone did not significantly impact MAG expression, except upon hyperoxic conditions in female cells, where a reduced MAG expression was observed. Hence the observed changes in the co-treatment seem to be attributed to $16 \alpha-\mathrm{OH}-$ DHEA. This shows that $16 \alpha-\mathrm{OH}$-DHEA might additionally activate other steroid hormone receptors apart from ER $\alpha$ and $E R \beta$. Hence, as observed throughout, it seems that $16 \alpha-\mathrm{OH}-$ DHEA has profound differences in its mechanism of action and that it could possibly have different interactions in the male and female cells. Therefore, it would be intriguing to further explore the stress response signaling evoked by $16 \alpha-\mathrm{OH}$-DHEA which might eventually be critical for designing new neuroprotective measures. 
A

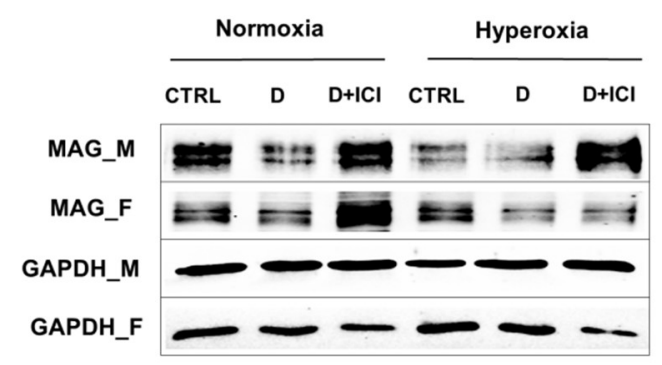

B

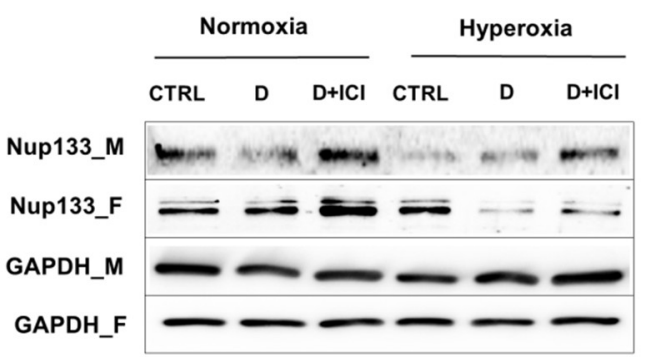

Male $\square$ Female

MAG

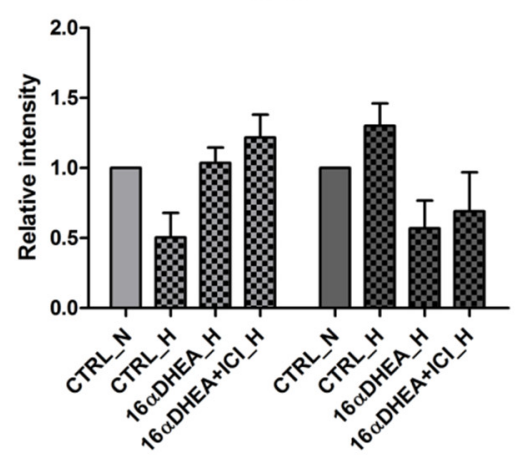

Nup133

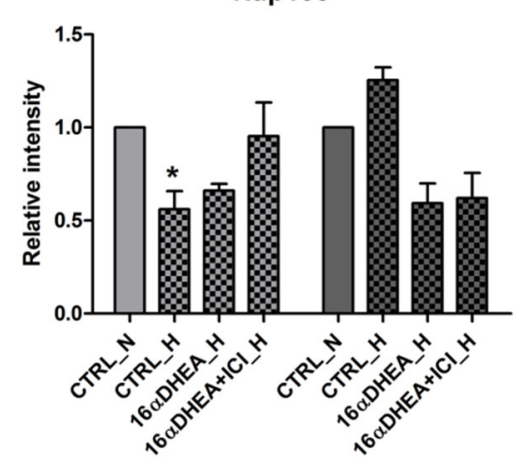

Figure 5. Mechanism of action of 16 $\alpha-\mathrm{OH}-\mathrm{DHEA}$ in male and female OPCs. Western blot results showing the expression of (A) MAG and (B) Nup133 in OPCs after treatment with $100 \mathrm{nM} \mathrm{16 \alpha -OH-DHEA} \mathrm{alone} \mathrm{and} \mathrm{16 \alpha -OH-DHEA} \mathrm{in} \mathrm{combination}$ with $1 \mu \mathrm{M}$ ICI (D+ICI) under normoxia and hyperoxia. All other data are representative of at least three independent experiments. Bars and error represent mean \pm SEM of replicate measurements. Significant differences from normoxia control are indicated by * $p<0.05$ (Student's $t$-test).

\section{Discussion}

Following preterm birth, the brain is left extremely vulnerable as it is deprived of essential supplies from the placenta including steroids, enzymes and nutrients and at the same time is prematurely exposed to stimulating environments such as hyperoxia and associated damage [29]. Steroid hormones have been long implicated in neuroprotection and so are some of the major steroid hormone precursor molecules such as DHEA and the neuroactive steroid Allopregnanolone, which are being increasingly investigated for their pharmacological importance [23,30]. Even though DHEA is one of the major secretory products of the human adrenal gland, the concentration of DHEA has been found to be particularly high in the brain. It is the glial cells in the brain that either metabolize DHEA from blood born precursors or synthesize it de novo from cholesterol, independent of peripheral steroidogenic sources [31,32]. Unlike DHEA, Allo and its biosynthetic enzymes, $5 \alpha$-reductase type I and $3 \alpha$-hydroxysteroid dehydrogenase, are expressed in neurons but not in the glial cells of rodent and human brain [33]. However, reduced concentrations of Allo have been linked to reduced myelination [34]. In preterm infants, even though there are high circulating levels of steroid precursors [35], their role in neuroprotection is not well defined and neither are their possible differential effects on male and female subjects.

Previous works from Heckmann et al. and other working groups $[35,36]$ have shown that fetal zonal steroids are synthesized in persistent high concentrations in premature babies for a considerable long duration. In this study, we performed a sex-based analysis on the concentration differences of FZS in preterm and term infants, and also in ill and well preterm infants, using the data collected from the first 3 days after birth. This period immediately after birth is characterized by the highest illness severity in preterm infants and 
therefore, this critical time period was specifically included for analysis in order to obtain a clearer picture of the differences in steroid concentrations that would be more relevant to be considered while making any correlations with experimental results. The data revealed striking differences between the male and female groups. The ill female infants showed a significant higher amount of total FZS. Previous studies on animal models have very clearly shown that preterm born male animals had reduced myelination and showed immaturity of the oligodendrocyte cell lineage after birth. The observed neurodevelopmental delay remained in the preterm male offspring even at term equivalent age [37]. Our data points towards the possibility that in the case of ill preterm infants, especially female infants, due to yet unknown reasons, the production of FZS by the adrenal cortex is still much more active than their healthy counterparts. And if this higher amount has been found in the urine, it might be very well possible that there exists a corresponding higher level in circulation as well. Therefore, this could lead to the buildup of a transient endogenous neuroprotection, rendering the female infants more protected towards the damages caused by perinatal stress. However, the role of individual steroids still need to be investigated in detail in both the sexes separately to understand the complex mechanisms behind any overall neuroprotective effect.

We have previously observed neuroprotective effects by estradiol, DHEA, $16 \alpha \mathrm{OH}-$ DHEA and Adiol in a model of hyperoxia-mediated cell death in the female derived immature oligodendroglial cell line (OLN93) [21]. We saw that DHEA, 16 $\alpha \mathrm{OH}$-DHEA and Adiol activated ER- $\alpha$ and/or ER- $\beta$ as a result of which a significant protection was achieved. At the same time, a co-treatment with estradiol in the presence of FZS did not add up to the already observed protection by FZS alone. However, the exact mechanisms and sex-based differences were not investigated. Therefore, in order to find more about the mechanisms of hyperoxia induced injury in oligodendrocytes, we performed a sex-based study on the differences in OPC maturation post hyperoxia and the results have shown how differentiation and Nrf1-oxidative stress responses are mediated by Nup133 in the male cells and the involvement of the classical estrogen receptor alpha $(E R \alpha)$ as a possible upstream regulator of Nup133 [22]. We saw that there exists a difference in the extent of regulation via ER $\alpha$ in the male and female cells with a possible stronger regulation in the female cells allowing them to better cope with the oxidative stress. In this study, we checked the effects of FZS, Allo and E2 on this mechanism and the maturation of OPCs. We show that these steroids have a differential effect on the male and female cells. Specifically, in post hyperoxic treatment we see that the FZS and Allo showed a positive effect on the maturation of the male OPCs, whereas, in the female OPCs, considering that the hyperoxic treatment itself did not hinder their maturation, no additional effect was observed. This was consistent upon treatment with E2 and co-treatment with $16 \alpha \mathrm{OH}$-DHEA in the female cells, but a negative effect of co-treatment was observed in the male cells post hyperoxia. From the mechanistic point of view, post hyperoxia, an overall additional effect was observed in the female cells via ER $\alpha$ upregulation. These results also illustrate that the FZS could be potential ligands of ER $\alpha$ and might protect the OPCs against oxidative stress via ER $\alpha$ activation. However, the effect of $16 \alpha \mathrm{OH}-\mathrm{DHEA}$ was notable as it showed a positive effect on maturation post hyperoxia in the male cells, but at the same time showed a decrease in Nup133 abundance and no up-regulation of ER $\alpha$ (Table 1). Considering that the total excreted FZS concentration associates with circulating levels and are higher in ill preterm female infants than in ill male infants (Figure 1B), we propose that the presence of these FZS render the female cells more resistant to oxidative stress compared to the males. This also makes it worth investigating in detail any changes in the concentration of these FZS in male and female infants under specific disease conditions. An overall combination effect, as mentioned above, must also be considered. Especially, considering the high amounts of circulating $16 \alpha \mathrm{OH}$-DHEA in preterm infants, it is important to perform further experiments to decipher its mechanism towards stress response.

We assume that this could be linked to the sex-based difference in the neurological outcome that has been observed over various clinical studies [4,38-40]. The experimental 
results with FZS treatment performed on male and female cells separately supports this hypothesis and show that this differential effect should be considered crucial for designing clinically effective neuroprotective strategies. As our results show that these FZSs can activate different mechanisms in male and female cells, more detailed studies would still be required to uncover the role of these FZS as potential pleotropic molecules that can interact with a number of steroid hormone receptors activating a myriad of distinct or overlapping signaling and mechanisms.

This study also throws light on the possible consequences of substituting estrogen in preterm infants without considering the presence of high amounts of circulating FZS and that these consequences can be largely influenced by sex. Particularly, the experimental results very clearly show a negative impact of co-treatment with $16 \alpha \mathrm{OH}$-DHEA on the described mechanism in the male cells. Since all these steroid molecules can have individual discrete effects as well as completely different regulatory mechanisms when present together with respect to stress response, it is logical to study these combinatory effects of endogenous and supplemental steroid metabolites in details. Even though, in a human system the situation is much more complex, these results point towards the first clues that demand further studies using various model systems to understand these complex interactions and their subsequent consequences without ignoring the sex-based differential aspects. Any future studies aiming at steroid supplementations or steroid-based therapies in preterm infants should also study the effects of the proposed steroids in combination with FZS and especially $16 \alpha \mathrm{OH}$-DHEA.

\section{Materials and Methods}

\subsection{Human Infant Urine Study}

This study was enrolled at the Justus Liebig University, Giessen. The study population consisted of two cohorts of preterm infants (gestational age $<30$ and 30-36 weeks) enrolled originally in a prospective longitudinally study to investigate adrenal glucocorticoid production by GC-MS in relation to illness and postnatal growth. [41,42]. Term infants with a gestational age >37 weeks were enrolled separately from March 2009 until July 2010.

Here, $24 \mathrm{~h}$ urine collections from the first three days after birth were analyzed as the severity of illness was expected to be highest during this period.

The urine collection procedure was performed as described previously [43]. In short, urine was collected for $24 \mathrm{~h}$ using disposable nappies composed of pure cellulose (Pampers; Procter \& Gamble, Schwalbach, Germany). Urine was extracted by compressing the nappies using a hydraulic press applying a maximum of $120 \mathrm{kPa} / \mathrm{cm}^{2}$. After centrifugation, the collected urinary specimens were stored at $-80{ }^{\circ} \mathrm{C}$ until analysis by GC-MS.

Urinary steroid profiles were determined by GC-MS analysis according to the procedure previously described [18]. A total of 17 FZS were determined by selected ion monitoring as listed in Table 2. To assess the overall secretion, these 17 major urinary metabolites were quantified (peak-area integration) and summed. Daily urinary excretion rates of the metabolites were corrected for body weight per micromoles creatinine to take into account changes in glomerular filtration rate during the first days of life [42]. 
Table 2. List of all 3ß-hydroxy-5-ene-steroids identified in human infant urine samples.

\begin{tabular}{|c|c|c|}
\hline & Metabolites & \\
\hline 1 & Adiol & 5-androstene- $3 \beta, 17 \beta$ diol \\
\hline 2 & 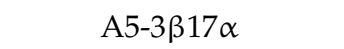 & 5-androstene- $3 \beta, 17 \alpha$ diol \\
\hline 3 & DHEA & 5 -androstene- 3 ßol-17-one \\
\hline 4 & $16 \alpha-\mathrm{OH}-\mathrm{DHEA}$ & 5-androstene- $3 \beta, 16 \alpha$-diol-17-one \\
\hline 5 & $16 \beta-\mathrm{OH}-\mathrm{DHEA}$ & 5 -androstene- $3 \beta, 16 \beta$-diol-17-one \\
\hline 6 & $15 \beta 16 \alpha-\mathrm{OH}-\mathrm{DHEA}$ & 5-androstene- $3 \beta, 15 \beta, 16 \alpha$-triol-17-one \\
\hline 7 & $16-\mathrm{O}-\mathrm{A} 5 \mathrm{D}$ & 5 -androstene- $3 \beta, 17 \beta$-diol-16-one \\
\hline 8 & A5T-16 $\alpha$ & 5 -androstene- $3 \beta, 16 \alpha, 17 \beta$-triol \\
\hline 9 & A5T-16 $\beta$ & 5 -androstene- $3 \beta, 16 \beta, 17 \beta$-triol \\
\hline 10 & $16 \propto 18-\mathrm{OH}-\mathrm{DHEA}$ & 5 -androstene- $3 \beta, 16 \alpha, 18$-triol-17-one \\
\hline 11 & $15 \beta 17 \alpha-\mathrm{OH}-\mathrm{P} 5$-olon & 5-pregnene-3 $\beta, 15 \beta, 17 \alpha$-triol-20-one \\
\hline 12 & $16 \alpha-\mathrm{OH}-\mathrm{P} 5-$ olon & 5 -pregnene- $3 \beta, 16 \alpha$-diol-20-one \\
\hline 13 & A53 $\beta 16 \alpha 17 \beta 18$-tetrol & 5 -androstene- $3 \beta, 16 \alpha, 17 \beta, 18$-tetrole \\
\hline 14 & A53 $\beta 15 \beta 16 \alpha 17 \beta$-tetrol & 5 -androstene- $3 \beta, 15 \beta, 16 \alpha, 17 \beta$-tetrole \\
\hline 15 & $15 \beta-\mathrm{OH}-\mathrm{P} 5$-tetrol & 5-pregnene-3 $\beta, 15 \beta, 17 \alpha, 20 \alpha$-tetrol \\
\hline 16 & 21-OH-P5-olon & 5-pregnene- $3 \beta, 21$-diol-20-one \\
\hline 17 & P5-3 $\beta 20 \alpha 21$-triol & 5 -pregnene- $3 \beta, 20 \alpha, 21$-triol \\
\hline 18 & P5-tetrol & 5-pregnene-3 $\beta, 16 \alpha, 20 \alpha, 21$-tetrole \\
\hline
\end{tabular}

Preterm infants with a gestational age of less than 30 weeks [17] and more than 30 weeks [23], who had no family history of adrenal illnesses and who had no major congenital anomalies, were eligible for the study. Postnatal steroid therapy was considered as a criterion for exclusion. Gestational age was determined using the expanded Ballard score and/or obstetrical dating.

Preterm infants were classified as being well according to previously described criteria [1]. Well infants had no signs of infection and did not receive treatment with surfactant or inotropes. Ill preterm infants suffered from one or more of the following diseases: respiratory-distress syndrome treated with surfactant, infection at birth (C-reactive protein $>10 \mathrm{mg} / \mathrm{L}$ and symptoms of an infection during the first $72 \mathrm{~h}$ of life), hospital infection (C-reactive protein $>10 \mathrm{mg} / \mathrm{L}$ and symptoms of an infection after the first $72 \mathrm{~h}$ of life), ventricular hemorrhage more than $\mathrm{II}^{\circ}$ according to the criteria described by Papile et al. [2] (Papile et al., 1978). Term infants were classified as being well when they received only routine care after delivery in the well-baby nursery of the department of obstetrics and were not admitted to the department of neonatology in the children's hospital.

\subsection{Animals}

Mouse protocols were approved by the Veterinary and Food Control Office, State Department of Agriculture, Food Safety and Fisheries Mecklenburg-Vorpommern, Germany (Permit Number: ZSF3936/11/17; Ethic approval date: 07 November 2017). Animal colonies were housed and maintained following the international FELASA, national GVsolas and local University Medicine Greifswald animal research guidelines. Crl:CD-1 (ICR) mice were received from the Charles River Company and bred for a maximum of two generations at the facility to obtain the donor mice and were used to generate oligodendrocyte precursor cells.

\subsection{Isolation and Culture of Mouse OPCs}

Mouse OPCs were isolated from enzymatically dissociated P2-P4 (postnatal day 2-4) old CD-1 (wild type strain) mice brains. For each isolation, tissue from the mid brain region comprising the sub ventricular zone from 3 male and 3 female (from the same litter) brains were pooled separately. The sex of the pups was determined visually and with genotyping. All animal usage for cell isolation was performed according to the institutional regulation regarding animal ethics. 
Isolated cells were cultured in serum free growth medium supplemented with $\mathrm{B}$ 27(w/o retinol), EGF $0.02 \mu \mathrm{g} / \mathrm{mL}$ and FGF $0.005 \mu \mathrm{g} / \mathrm{mL}$ under $3 \% \mathrm{O}_{2}$ conditions. After $\sim 5-6$ days when the neurospheres were around $100 \mu \mathrm{m}$ in diameter, the neurosphere growth medium was gradually replaced by serum free B104CM containing oligosphere medium every alternate day for 2 weeks. After this time period, the cells were trypsinized and used for experiments. Detailed protocol for the isolation and culture of mouse OPCs has been published in Nature Protocol Exchange [44].

\subsection{Treatment with Hyperoxia}

For differentiation experiments, the male and female derived OPCs were trypsinized separately, the cells were counted and seeded in equal densities into 6 well plates for adherent cells (without any coating; Cell+, Sarstedt, Nümbrecht Germany) containing $1 \mathrm{~mL}$ oligosphere medium per well. The cells were first given $80 \% \mathrm{O}_{2}$ shock for $24 \mathrm{~h}$, after which, $1 \mathrm{~mL}$ fresh media was added to each well and all plates were returned to $3 \% \mathrm{O}_{2}$ (normoxia) condition. The cells were then allowed to differentiate for 4 days with $1 \mathrm{~mL}$ medium change every alternate day.

For protein studies, the cells from male and female derived OPCs were trypsinized, counted, and seeded in equal densities into 6 well plates for adherent cells (without any coating; Cell+, Sarstedt, Nümbrecht Germany) containing $1 \mathrm{~mL}$ DMEM/F12 + 45\% glucose solution ( $666 \mu \mathrm{L}$ for $50 \mathrm{~mL}$ DMEM/F12) medium per well. The plates were then kept at $80 \%$ $\mathrm{O}_{2}, 5 \% \mathrm{CO}_{2}$ and $37^{\circ} \mathrm{C}$ (hyperoxia) and $3 \% \mathrm{O}_{2}, 5 \% \mathrm{CO}_{2}$ and $37^{\circ} \mathrm{C}$ (normoxia) incubators respectively, for $24 \mathrm{~h}$. Cells were subjected to protein and RNA extraction immediately after the treatment time. All cells (adhered and suspended) from each well were used for further processing and analysis.

\subsection{Treatment with Steroids}

For differentiation experiments as well as for protein studies, the procedure was followed exactly as mentioned above with addition of FZS or E2 before giving the oxygen shock.

A final concentration of $100 \mathrm{nM}$ was used for treatment in the case of all the steroid molecules tested.

The estrogen receptor antagonist, ICI 182, 780 (ICI) was administered in a final concentration of $1 \mu \mathrm{M}$.

\subsection{Cell Lines}

B104 Neuroblastoma cell line was purchased from the American Type Culture Collection (ATCC). The cells were used only for preparing conditioned media for OPC culture as described previously [44].

\subsection{Immunoblot Analysis}

Protein extracts from whole cell lysates containing $\sim 40 \mu \mathrm{g}$ protein was loaded in each lane of a Mini-Gel module for electrophoresis (BioRad, Munich, Germany). Protein was transferred onto nitrocellulose membrane (Amersham Protran $0.45 \mu \mathrm{m}$ NC Western Blotting Membrane, GE Healthcare, Chicago, IL, USA), blocked with $1 \times$ Blocking buffer (Pierce $^{\mathrm{TM}}$ Protein-Free (TBS) Blocking Buffer, Thermo Fisher, Waltham, MA, USA) at RT for $1 \mathrm{~h}$, and incubated in primary antibody at $4{ }^{\circ} \mathrm{C}$ overnight. GAPDH (Rabbit Anti-GAPDH (D16H11) mAb, Cell Signaling Technology, Danvers, MA, USA) was used as the loading control at 1:1000 dilution. The other primary antibodies used were: Mouse Anti-Estrogen receptor alpha (33) mAb (MA1-310), Thermo Fischer Scientific, Waltham, MA, USA; Rabbit Anti-MAG mAb (D4G3) (9043), Cell Signaling Technology, Danvers, Massachusetts, USA; Anti-Rabbit NUP133 Polyclonal(12405-1-AP), Proteintech, Rosemont, Illinois, USA. Blots were incubated with secondary antibody at 1:10,000 dilution in blocking buffer for $1 \mathrm{~h}$ at RT. Protein bands were visualized with SuperSignal ${ }^{\mathrm{TM}}$ West Femto Maximum Sensitivity Chemiluminescence Substrate (Thermo Fischer Scientific, Waltham, MA, USA). Densitometric intensities were calculated using ImageLab software (BioRad, Munich, Germany). 
GAPDH signal intensity was used for normalization of data before relative intensity to CTRL_N for each individual condition was calculated.

\subsection{Experimental Design and Statistical Analysis}

The statistical analysis for Western blot data was performed using GraphPad Prism 5 for Windows (Source: GraphPad Software, San Diego, CA, USA; http: / www.graphpad. $\mathrm{com} /$; accessed date: 14 April 2021 (RRID:SCR_002798). Data from all bio-replicates (minimum 3 for each experiment) for each experiment was plotted with the mean value and standard error bars (standard error of mean, SEM). For statistical comparison between two variables, unpaired Student's $t$-test was used and One way ANOVA (one-way analysis of variance) with Tukey's/Dunnet's post-hoc test was applied to compare between multiple treatment groups. A variance with a $p$ value $<0.05$ was considered significant. Various levels of significance were depicted as follows: ${ }^{*} p<0.05$; ${ }^{* *} p<0.01$; ${ }^{* * *} p<0.001$.

Details of the statistical analysis used for generating the urine steroid profile data are mentioned in the results section. Twenty-four-hour urinary steroid excretion rates of the first three days of life were summed to generate an integral parameter of FZS production. All analyses were performed using the Stata version 15.1 software (Stata Corporation, College Station, Texas, USA).

Author Contributions: Conceptualization, D.E.S., S.A.W. and M.H.; methodology, D.E.S., E.H., S.H. and E.L.K.; investigation, D.E.S. and E.H.; steroid analysis: M.F.H. and S.A.W.; formal analysis, D.E.S., T.I. and E.H.; writing—original draft, D.E.S.; writing—review and editing, D.E.S., E.H., S.A.W., M.F.H. and M.H.; funding acquisition, M.H.; resources, U.V.; supervision, M.H. and E.H. All authors have read and agreed to the published version of the manuscript.

Funding: This work was funded by the Department of Neonatology and Pediatric Intensive Care, University Medicine Greifswald (Annual budget for scientific research). The data from human infant urine samples was generated from work supported by a grant of the Deutsche Forschungsgemeinschaft (DFG) to M.H. and S.A.W. (HE 3557/1-1) (preterm cohort) and by start-up funding of the University Medicine Giessen to M.H. and S.A.W. (term cohort).

Institutional Review Board Statement: This study was approved by the Ethics Committee of the Justus Liebig University of Giessen (reference number 04/02; ethic approval date: 15.04.2002) and confirms to the World Medical Association Declaration of Helsinki regulatory standards.

Informed Consent Statement: A written informed parental consent was obtained from all the subjects included in this study.

Acknowledgments: We are indebted to Markus M. Lerch, Department of Inner Medicine A and Agnes Flöel and Antje Vogelgesang, Department of Neuroimmunology, University Medicine Greifswald, for sharing their lab facility for this work and Monika Hoyer for technical assistance. We acknowledge support for the Article Processing Charge from the DFG (German Research Foundation, 393148499) and the Open Access Publication Fund of the University of Greifswald.

Conflicts of Interest: The authors declare no conflict of interest. 


\section{Appendix A}

A

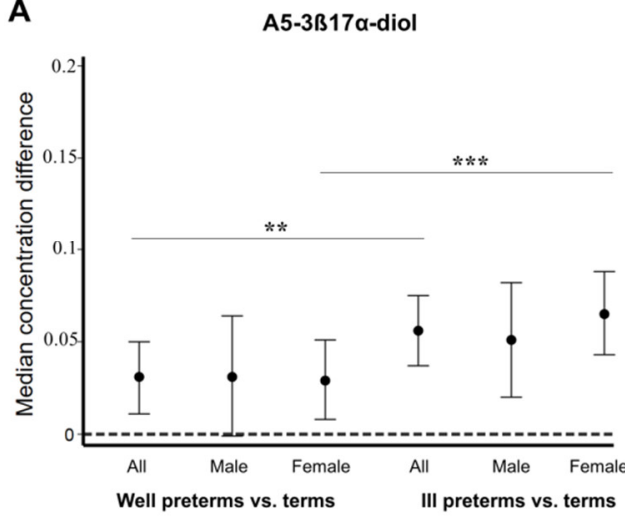

B

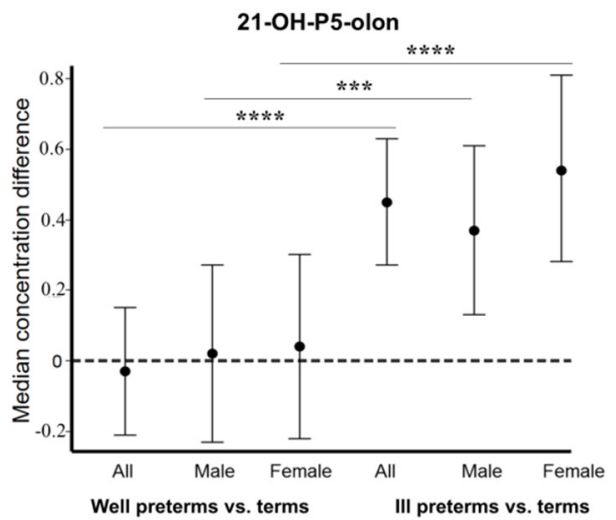

Figure A1. Concentration differences of selected individual FZS. Comparison of (A) A5-3 $\beta 17 \alpha$-diol and (B) 21-OH-P5-olon excretion in healthy male preterm $(<37$ weeks gestational age, $n=42)$ and healthy female preterm $(<37$ weeks gestational age, $n=29)$ infants compared to sick male preterm ( $<37$ weeks gestational age, $n=38)$ and sick female preterm $(<37$ weeks gestational age, $n=26$ ) infants during the first three days after birth. ${ }^{* *} p<0.01,{ }^{* * *} p<0.001,{ }^{* * *} p<0.0001$ (median regression models). The beta coefficients and the belonging $95 \%$ confidence intervals were plotted. A whole $95 \%$ confidence interval above 0 is considered statistically significant.

\section{References}

1. Linsell, L.; Johnson, S.; Wolke, D.; O'Reilly, H.; Morris, J.K.; Kurinczuk, J.J.; Marlow, N. Cognitive trajectories from infancy to early adulthood following birth before 26 weeks of gestation: A prospective, population-based cohort study. Arch. Dis. Child. 2018, 103, 363-370. [CrossRef]

2. Woythaler, M. Neurodevelopmental outcomes of the late preterm infant. Semin. Fetal Neonatal Med. 2019, 24, 54-59. [CrossRef]

3. Novak, C.M.; Ozen, M.; Burd, I. Perinatal Brain Injury: Mechanisms, Prevention, and Outcomes. Clin. Perinatol. 2018, 45, $357-375$. [CrossRef] [PubMed]

4. O'Driscoll, D.N.; McGovern, M.; Greene, C.M.; Molloy, E.J. Gender disparities in preterm neonatal outcomes. Acta Paediatr. 2018. [CrossRef] [PubMed]

5. Schumacher, M.; Hussain, R.; Gago, N.; Oudinet, J.P.; Mattern, C.; Ghoumari, A.M. Progesterone synthesis in the nervous system: Implications for myelination and myelin repair. Front. Neurosci. 2012, 6, 10. [CrossRef] [PubMed]

6. Ishida, T.; Seo, F.; Hirato, K.; Fukuda, T.; Yanaihara, T.; Araki, H.; Nakayama, T. Changes in placental enzymatic activities in relation to estrogen production during pregnancy. Nihon Sanka Fujinka Gakkai Zasshi 1985, 37, 547-554.

7. Wood, C.E. Estrogen/hypothalamus-pituitary-adrenal axis interactions in the fetus: The interplay between placenta and fetal brain. J. Soc. Gynecol. Investig. 2005, 12, 67-76. [CrossRef] [PubMed]

8. Coumailleau, P.; Pellegrini, E.; Adrio, F.; Diotel, N.; Cano-Nicolau, J.; Nasri, A.; Vaillant, C.; Kah, O. Aromatase, estrogen receptors and brain development in fish and amphibians. Biochim. Biophys. Acta 2015, 1849, 152-162. [CrossRef]

9. Rao, M.L.; Kolsch, H. Effects of estrogen on brain development and neuroprotection-implications for negative symptoms in schizophrenia. Psychoneuroendocrinology 2003, 28 (Suppl. 2), 83-96. [CrossRef]

10. Gerstner, B.; Lee, J.; DeSilva, T.M.; Jensen, F.E.; Volpe, J.J.; Rosenberg, P.A. 17beta-estradiol protects against hypoxic/ischemic white matter damage in the neonatal rat brain. J. Neurosci. Res. 2009, 87, 2078-2086. [CrossRef]

11. Gerstner, B.; Sifringer, M.; Dzietko, M.; Schuller, A.; Lee, J.; Simons, S.; Obladen, M.; Volpe, J.J.; Rosenberg, P.A.; Felderhoff-Mueser, U. Estradiol attenuates hyperoxia-induced cell death in the developing white matter. Ann. Neurol. 2007, 61, 562-573. [CrossRef]

12. Guo, H.; Liu, M.; Zhang, L.; Wang, L.; Hou, W.; Ma, Y. The Critical Period for Neuroprotection by Estrogen Replacement Therapy and the Potential Underlying Mechanisms. Curr. Neuropharmacol. 2020, 18, 485-500. [CrossRef]

13. Trotter, A.; Maier, L.; Pohlandt, F. Management of the extremely preterm infant: Is the replacement of estradiol and progesterone beneficial? Paediatr. Drugs 2001, 3, 629-637. [CrossRef] [PubMed]

14. Siiteri, P.K.; MacDonald, P.C. Placental estrogen biosynthesis during human pregnancy. J. Clin. Endocrinol. Metab. 1966, 26, 751-761. [CrossRef]

15. Hubner, S.; Reich, B.; Heckmann, M. Role of sex steroids and their receptors in human preterm infants: Impacts on future treatment strategies for cerebral development. Biochem. Pharmacol. 2015, 98, 556-563. [CrossRef]

16. Ishimoto, H.; Jaffe, R.B. Development and function of the human fetal adrenal cortex: A key component in the feto-placental unit. Endocr. Rev. 2011, 32, 317-355. [CrossRef]

17. Midgley, P.C.; Russell, K.; Oates, N.; Holownia, P.; Shaw, J.C.; Honour, J.W. Adrenal function in preterm infants: ACTH may not be the sole regulator of the fetal zone. Pediatr. Res. 1998, 44, 887-893. [CrossRef] 
18. Heckmann, M.; Hartmann, M.F.; Kampschulte, B.; Gack, H.; Bodeker, R.H.; Gortner, L.; Wudy, S.A. Persistent high activity of the fetal adrenal cortex in preterm infants: Is there a clinical significance? J. Pediatr. Endocrinol. Metab. 2006, 19, 1303-1312. [CrossRef] [PubMed]

19. Grueters, A.; Korth-Schutz, S. Longitudinal study of plasma dehydroepiandrosterone sulfate in preterm and fullterm infants. $J$. Clin. Endocrinol. Metab. 1982, 55, 314-320. [CrossRef] [PubMed]

20. Kari, M.A.; Raivio, K.O.; Stenman, U.H.; Voutilainen, R. Serum cortisol, dehydroepiandrosterone sulfate, and steroid-binding globulins in preterm neonates: Effect of gestational age and dexamethasone therapy. Pediatr. Res. 1996, 40, 319-324. [CrossRef]

21. Hubner, S.; Sunny, D.E.; Pohlke, C.; Ruhnau, J.; Vogelgesang, A.; Reich, B.; Heckmann, M. Protective Effects of Fetal Zone Steroids Are Comparable to Estradiol in Hyperoxia-Induced Cell Death of Immature Glia. Endocrinology 2017, 158, 1419-1435. [CrossRef]

22. Sunny, D.E.; Hammer, E.; Strempel, S.; Joseph, C.; Manchanda, H.; Ittermann, T.; Hubner, S.; Weiss, F.U.; Volker, U.; Heckmann, M. Nup133 and ERalpha mediate the differential effects of hyperoxia-induced damage in male and female OPCs. Mol. Cell Pediatr 2020, 7, 10. [CrossRef]

23. Greaves, R.F.; Wudy, S.A.; Badoer, E.; Zacharin, M.; Hirst, J.J.; Quinn, T.; Walker, D.W. A tale of two steroids: The importance of the androgens DHEA and DHEAS for early neurodevelopment. J. Steroid Biochem Mol. Biol 2019, 188, 77-85. [CrossRef] [PubMed]

24. Hampl, R.; Starka, L. Mini review: 16alpha-hydroxylated metabolites of dehydroepiandrosterone and their biological significance. Endocr. Regul. 2000, 34, 161-163.

25. Schweigmann, H.; Sanchez-Guijo, A.; Ugele, B.; Hartmann, K.; Hartmann, M.F.; Bergmann, M.; Pfarrer, C.; Doring, B.; Wudy, S.A.; Petzinger, E.; et al. Transport of the placental estriol precursor 16alpha-hydroxy-dehydroepiandrosterone sulfate (16alphaOH-DHEAS) by stably transfected OAT4-, SOAT-, and NTCP-HEK293 cells. J. Steroid Biochem. Mol. Biol. 2014, 143, $259-265$. [CrossRef]

26. Trotter, A.; Pohlandt, F. The replacement of oestradiol and progesterone in very premature infants. Ann. Med. 2000, 32, 608-614. [CrossRef] [PubMed]

27. Trotter, A.; Bokelmann, B.; Sorgo, W.; Bechinger-Kornhuber, D.; Heinemann, H.; Schmucker, G.; Oesterle, M.; Kohntop, B.; Brisch, K.H.; Pohlandt, F. Follow-up examination at the age of 15 months of extremely preterm infants after postnatal estradiol and progesterone replacement. J. Clin. Endocrinol. Metab. 2001, 86, 601-603. [CrossRef]

28. Trotter, A.; Steinmacher, J.; Kron, M.; Pohlandt, F. Neurodevelopmental follow-up at five years corrected age of extremely low birth weight infants after postnatal replacement of 17beta-estradiol and progesterone. J. Clin. Endocrinol. Metab. 2012, 97, 1041-1047. [CrossRef] [PubMed]

29. Alur, P. Sex Differences in Nutrition, Growth, and Metabolism in Preterm Infants. Front. Pediatr. 2019, 7, 22. [CrossRef]

30. Shaw, J.C.; Dyson, R.M.; Palliser, H.K.; Gray, C.; Berry, M.J.; Hirst, J.J. Neurosteroid replacement therapy using the allopregnanolone-analogue ganaxolone following preterm birth in male guinea pigs. Pediatr. Res. 2019, 85, 86-96. [CrossRef] [PubMed]

31. Warner, M.; Gustafsson, J.A. DHEA-A precursor of ERbeta ligands. J. Steroid Biochem. Mol. Biol. 2015, 145, 245-247. [CrossRef]

32. Friess, E.; Schiffelholz, T.; Steckler, T.; Steiger, A. Dehydroepiandrosterone-A neurosteroid. Eur J. Clin. Investig. 2000, 30 (Suppl. 3), 46-50. [CrossRef] [PubMed]

33. Pinna, G. Allopregnanolone, the Neuromodulator Turned Therapeutic Agent: Thank You, Next? Front. Endocrinol (Lausanne) 2020, 11, 236. [CrossRef]

34. Bennett, G.A.; Palliser, H.K.; Walker, D.; Hirst, J. Severity and timing: How prenatal stress exposure affects glial developmental, emotional behavioural and plasma neurosteroid responses in guinea pig offspring. Psychoneuroendocrinology 2016, 70, 47-57. [CrossRef]

35. Travers, S.; Martinerie, L.; Boileau, P.; Lombes, M.; Pussard, E. Alterations of adrenal steroidomic profiles in preterm infants at birth. Arch. Dis. Child. Fetal Neonatal Ed. 2018, 103, F143-F151. [CrossRef] [PubMed]

36. Midgley, P.C.; Russell, K.; Oates, N.; Shaw, J.C.; Honour, J.W. Activity of the adrenal fetal zone in preterm infants continues to term. Endocr. Res. 1996, 22, 729-733. [CrossRef]

37. Hirst, J.J.; Cumberland, A.L.; Shaw, J.C.; Bennett, G.A.; Kelleher, M.A.; Walker, D.W.; Palliser, H.K. Loss of neurosteroid-mediated protection following stress during fetal life. J. Steroid Biochem. Mol. Biol. 2016, 160, 181-188. [CrossRef]

38. Battarbee, A.N.; Glover, A.V.; Vladutiu, C.J.; Gyamfi-Bannerman, C.; Aliaga, S.; Manuck, T.A.; Boggess, K.A. Sex-Specific Differences in Late Preterm Neonatal Outcomes. Am. J. Perinatol. 2019, 36, 1223-1228. [CrossRef] [PubMed]

39. Hindmarsh, G.J.; O'Callaghan, M.J.; Mohay, H.A.; Rogers, Y.M. Gender differences in cognitive abilities at 2 years in ELBW infants. Extremely low birth weight. Early Hum. Dev. 2000, 60, 115-122. [CrossRef]

40. Hintz, S.R.; Kendrick, D.E.; Vohr, B.R.; Kenneth Poole, W.; Higgins, R.D. Gender differences in neurodevelopmental outcomes among extremely preterm, extremely-low-birthweight infants. Acta Paediatr. 2006, 95, 1239-1248. [CrossRef] [PubMed]

41. Grofer, B.; Bodeker, R.H.; Gortner, L.; Heckmann, M. Maturation of adrenal function determined by urinary glucocorticoid steroid excretion rates in preterm infants of more than 30 weeks of gestational age. Neonatology 2010, 98, 200-205. [CrossRef] [PubMed]

42. Heckmann, M.; Hartmann, M.F.; Kampschulte, B.; Gack, H.; Bodeker, R.H.; Gortner, L.; Wudy, S.A. Cortisol production rates in preterm infants in relation to growth and illness: A noninvasive prospective study using gas chromatography-mass spectrometry. J. Clin. Endocrinol. Metab. 2005, 90, 5737-5742. [CrossRef] [PubMed] 
43. Heckmann, M.; Hartmann, M.F.; Kampschulte, B.; Gack, H.; Bodeker, R.H.; Gortner, L.; Wudy, S.A. Assessing cortisol production in preterm infants: Do not dispose of the nappies. Pediatr. Res. 2005, 57, 412-418. [CrossRef] [PubMed]

44. Sunny, D.E.; Muzzio, D.O.; Heckmann, M. Method for generating highly pure culture of mouse derived Oligospheres under hypoxic conditions. Protoc. Exch. 2015. [CrossRef] 